\title{
Retraction Note to: In-silico Analysis of LncRNA-mRNA Target Prediction
}

\author{
Deepanjali Sharma and Gaurav Meena
}

Retraction Note to:

Chapter "In-silico Analysis of LncRNA-mRNA Target

Prediction" in: D. Reddy Edla et al. (eds.), Advances

in Machine Learning and Data Science, Advances

in Intelligent Systems and Computing 705, https://doi.org/10.1007/978-981-10-8569-7_28

The authors have retracted this chapter [1] because upon re-review of the methodology, errors have been identified in the presented algorithm. Therefore, the results are incorrect. All authors agree to this retraction.

[1] Sharma D., Meena G. (2018) In-silico Analysis of LncRNA-mRNA Target Prediction. In: Reddy Edla D., Lingras P., Venkatanareshbabu K. (eds) Advances in Machine Learning and Data Science. Advances in Intelligent Systems and Computing, vol 705. Springer, Singapore; https://link.springer.com/chapter/10.1007/ 978-981-10-8569-7_28.

The retracted online version of this chapter can be found at https://doi.org/10.1007/978-981-10-8569-7_28 